\title{
Reexamination of Real Business Cycles in A Small Open Economy*
}

\author{
Jang-Ting Guo \\ University of California, Riverside ${ }^{\dagger}$ \\ Zuzana Janko \\ University of Calgary
}

January 29, 2008

\begin{abstract}
Standard dynamic small open economy models have predicted a counterfactual perfectly positive correlation between output and hours worked over the business cycle. In addition, this class of models exhibits a weak internal propagation mechanism. To address these anomalies, this paper incorporates intertemporally non-separable labor supply and variable capital utilization into the canonical Mendoza model with adjustment costs of net investment. Our analysis shows that a dynamic, technology-shock driven small open economy model with internal habit formation in labor hours and endogenous capital utilization is able to account for the main real business cycle regularities of Canada after 1981.
\end{abstract}

Keywords: Real Business Cycles, Small Open Economy, Capital Utilization, Habit Formation.

JEL Classification: E32, F41.

\footnotetext{
${ }^{*}$ We thank Hung-Ju Chen, Dean Corbae, Yu-Ning Hwang, Hashmat Khan, Francisco Gonzalez, Sharon Harrison, Enrique Mendoza, Eric Leeper, Marc-André Letendre, Stephanie Schmitt-Grohé, Richard Suen, Martin Uribe and seminar participants at University of Calgary, the 2007 Annual Meetings of the Canadian Economics Association, the 2007 North American Summer Meeting of the Econometric Society, and the 2007 Far Eastern Meeting of the Econometric Society for helpful discussions and comments. Of course, all remaining errors are our own.

${ }^{\dagger}$ Corresponding Author. Department of Economics, 4128 Sproul Hall, University of California, Riverside, CA, 92521, USA, Phone: (951) 827-1588, Fax: (951) 827-5685, E-mail: guojt@ucr.edu.

${ }^{\ddagger}$ Department of Economics, University of Calgary, 2500 University Drive, N.W., Calgary, Alberta, Canada T2N 1N4, Phone: (403) 220-6101, Fax: (403) 282-5262, E-mail: zjanko@ucalgary.ca.
} 


\section{Introduction}

Since the influential work of Mendoza (1991), it is now well known that dynamic stochastic general equilibrium models, specifically the real-business-cycle approach, can successfully explain some important stylized facts of a small open economy with incomplete asset markets in which domestic households only have access to a one-period risk free foreign bond. In particular, Mendoza's model correctly predicts that the correlation between savings and investment rates is positive, and that the balance of trade moves countercyclically with output over the business cycle. As pointed out by Correia, Neves and Rebelo (1995), the ability of this class of models to mimic key international indicators of a small open economy depends crucially on adopting the period utility function postulated by Greenwood, Hercowitz and Huffman (GHH, 1988) whereby there is no income effect associated with the household's labor supply decision. As a result, the elasticity of intertemporal substitution in hours worked (or leisure) is zero.

On the other hand, studies in this line of research have produced a set of clearly identified anomalies. One of the most robust puzzles, caused by the GHH preferences combined with a Cobb-Douglas production technology, is the perfectly positive correlation between detrended GDP and labor hours. Motivated by this counterfactual inconsistency, Schmitt-Grohé and Uribe's (2003, section 8.1) sensitivity analysis shows that a dynamic small open economy model which allows for a wealth effect in labor supply does not perform as well as that under the GHH utility formulation, e.g., the model-generated time series of consumption is too smooth compared to the observed variability, and the trade balance becomes procyclical.

Moreover, this type of small open real business cycle models, similar to the corresponding closed-economy version, exhibits a weak internal propagation mechanism. Using the productivity-disturbance process that Letendre (2004) estimates from Canadian quarterly data since 1981, we find that in Mendoza's model with capital adjustment costs, output is less volatile than that observed in the actual economy; moreover, the coefficients of serial correlation in GDP, investment and work effort are all statistically lower than their empirical counterparts. ${ }^{1}$ In addition, this benchmark specification exaggerates the negative correlations between GDP and the ratios of trade balance and current account to output.

To address the above-mentioned anomalies, this paper incorporates intertemporally non-

\footnotetext{
${ }^{1}$ By contrast, this anomaly does not arise in Mendoza (1991) and Schmitt-Grohé and Uribe (2003) because they calibrate the persistence parameter for the technology shock and the standard deviation of its innovations so that the resulting artificial time series of output displays the same volatility and first-order serial correlation as those in the Canadian annual data, 1946 - 1985.
} 
separable labor supply (or leisure) and variable capital utilization into Mendoza's one-sector, dynamic small open economy model with adjustment costs of net investment. Furthermore, in order to highlight the cyclical effects of these two additional features, productivity disturbances are postulated to be the only driving process for generating macroeconomic fluctuations. Most studies in the existing literature employ the GHH preferences that are separable over time, which in turn contributes to the perfectly positive correlation between output and employment. To overcome this counterfactual result, as in Kydland and Prescott (1982) and Lettau and Uhlig (2000) for closed-economy real business cycle models, we consider a time nonseparable utility function that exhibits non-zero elasticities of substitution in hours worked across different periods. In addition, based on the empirical findings of Hotz, Kydland and Sedlacek (1988), Eichenbaum, Hansen and Singleton (1988) and Wen (1998), the formulation with either intertemporal substitutability (i.e. the fatigue effects) or complementarity (i.e. internal habit formation) of work effort is examined in our analyses. ${ }^{2}$

We also follow Letendre (2004) and strengthen the model's endogenous propagation mechanism by allowing for variable capital utilization. Specifically, a more intensive utilization of capital is assumed to accelerate its rate of depreciation. In a symmetric equilibrium, the social technology displays a larger elasticity of output with respect to both the technology shock and labor inputs than those in the original Mendoza economy. As a result, varying capital utilization amplifies the business-cycle effects of productivity disturbances since it provides an additional margin to change output. It follows that as in closed-economy real business cycle models (see Burnside, Eichenbaum and Rebelo, 1993; Burnside and Eichenbaum, 1996, among others), smoother technology shocks are needed to match the observed volatility of GDP.

We obtain simulated second moments and impulse response functions from six versions of our model economy, and then compare them with the H-P filtered, post-1981 Canadian quarterly data documented by Letendre (2004). The first three models exhibit time-invariant capital utilization and depreciation rates. As discussed earlier, our benchmark specification (Model 1) corresponds to Mendoza's one-sector, dynamic small open economy model subject to the productivity-disturbance process estimated by Letendre (2004). When the household's current and previous choices of hours worked are included in its period utility function either as substitutes (Model 1a) or complements (Model 1b), we show that both models perform

\footnotetext{
${ }^{2}$ Letendre (2004) incorporates internal habit formation in consumption into the Mendoza economy with capital adjustment costs. In this case, the perfectly positive correlation between output and hours worked remains unchanged.
} 
no worse than the baseline configuration at matching the contemporaneous correlations with GDP; whereas the model's predictions of the serial correlations in key macroeconomic aggregates are significantly improved because of the presence of labor persistence. Moreover, allowing for intertemporal substitution raises the elasticity of labor supply with respect to changes in its marginal productivity, which in turn leads to more variable hours worked and GDP compared to those in Model 1. However, output volatility in this case remains lower than what the Canadian economy displays. By contrast, intertemporal complementarity of labor hours dampens the cyclical effects of technology shocks, thus work effort and output become less variable in comparison with the benchmark Model 1.

With a time nonseparable preference formulation, the household's period- $t$ labor supply decision takes into account its expected influence on future utilities, hence GDP and hours worked are no longer perfectly correlated. Compared to Model 1, intertemporal substitutability generates higher initial increases of labor hours and output in response to a positive transient technology shock, and then they display similar oscillatory dynamics before falling back gradually to the steady state. As a result, the correlation between output and employment remains statistically too high (0.99) vis-á-vis the Canadian data (0.91). On the contrary, intertemporal complementarity leads to weaker initial responses of hours worked and output than those in Model 1. The associated sluggish movement in the household's labor supply decision makes GDP and work effort continue to rise after the impact period in spite of a decreasing marginal productivity of labor, thereby generating hump-shaped impulse response functions. Moreover, the subsequent adjustment paths of hours worked and output are not closely synchronized in that labor now becomes a lagging variable of the business cycle. This will result in a lower correlation coefficient between GDP and employment (0.92) that is remarkably close to the Canadian economy.

The remaining three models exhibit time-varying capital utilization and depreciation rates, and they are driven by a smoother technology-shock process that Letendre (2004) also estimates from the post-1981 Canadian quarterly data. It turns out that even with a $13.36 \%$ reduction in the standard deviation of the driving productivity innovations, all variables in these specifications display substantially higher volatilities than their fixed-utilization counterparts. Moreover, since the persistence parameter of productivity disturbances remains virtually unchanged, incorporating variable capital utilization does not significantly influence the model's predictions of autocorrelations, contemporaneous correlations with output and 
the savings-investment comovement.

As in the benchmark Model 1, the no-labor-persistence Models 2 continues to show a counterfactual perfectly positive correlation between output and employment, and statistically lower serial correlations in GDP and hours worked than those observed in the data. On the other hand, Model $2 a$ (with intertemporal substitutability) "overshoots" the volatilities of output, consumption and investment, and underpredicts the autocorrelations in GDP and labor hours. By contrast, the formulation with intertemporal complementarity (Model 2b) produces a statistically close match with the observed variabilities of output, consumption, investment and the trade-balance-to-output ratio. It also successfully matches the persistence of GDP, consumption, investment, work effort, and the ratios of trade balance and current account to output.

In terms of impulse response functions for the three models with variable capital utilization, the impact responses of hours worked and GDP to a transitory positive technology shock are stronger because of a larger equilibrium output elasticity. Higher work effort also leads to more intensive utilization of capital, which in turn contributes to a further immediate rise in output. Moreover, the ensuing dynamic paths of labor hours and GDP are qualitatively identical to those in their constant-utilization counterparts. If follows that the correlation coefficient between output and employment will not be affected by the addition of variable capital utilization alone. In sum, our analysis shows that a dynamic, technology-shock driven small open economy model with internal labor habits and variable capital utilization is able to account for the main real business cycle regularities of Canada after 1981.

The remainder of this paper is organized as follows. Section 2 describes the model economy and analyzes its equilibrium conditions. Section 3 calibrates the model's parameters and discusses simulation results. Section 4 concludes.

\section{The Economy}

This paper incorporates intertemporally nonseparable labor supply (or leisure) and variable capital utilization into Mendoza's (1991) one-sector, small open real business cycle model driven solely by productivity disturbances. Moreover, in order to resolve the well-known unit root problem associated with foreign asset accumulation, we follow Schmitt-Grohé and Uribe (2003) and adopt a simplified Uzawa's (1968) preference specification in which the household's discount factor is a function of per-capita, rather than individual, levels of consumption and 
hours worked. ${ }^{3}$

The economy is populated by a unit measure of identical infinitely-lived households, each endowed with one unit of time and maximizes its expected lifetime utility

$$
E_{0} \sum_{t=0}^{\infty} \theta_{t} U\left(c_{t}, h_{t}, h_{t-1}\right), \quad h_{-1}>0 \text { given, }
$$

where $E$ is the conditional expectations operator, and $c_{t}$ and $h_{t}$ are the individual household's current consumption and hours worked, respectively. We also allow for persistence in labor supply as $h_{t-1}$ enters the household's period- $t$ utility function given by

$$
\begin{aligned}
U\left(c_{t}, h_{t}, h_{t-1}\right) & =\frac{\left[c_{t}-\frac{A}{\omega}\left(h_{t}+\alpha h_{t-1}\right)^{\omega}\right]^{1-\gamma}-1}{1-\gamma}, \\
A & >0, \omega>1, \alpha>-1, \gamma>0 \text { and } \gamma \neq 1
\end{aligned}
$$

Notice that the GHH (or no-income-effect) preference formulation, adopted by Mendoza (1991) and Schmitt-Grohé and Uribe (2003), corresponds to the case of $\alpha=0$ whereby households derive disutility only from their contemporaneous work effort. When $\alpha>0$, it is straightforward to show that $\frac{\partial U(\cdot) / \partial h_{t}}{\partial h_{t-1}}<0$, thus the current and past values of hours worked are intertemporal substitutes (Kydland and Prescott, 1982) that capture the fatigue effects. By contrast, $h_{t}$ and $h_{t-1}$ become intertemporal complements when $\alpha<0$, hence the model exhibits internal habit formation in labor supply. ${ }^{4}$ For completeness of the analysis, we will investigate all three possibilities below.

Regarding the time-preference function $\theta_{t}$, we modify Schmitt-Grohé and Uribe's (2003) specification to account for the presence of labor persistence with $\theta_{0}=1$ and

$$
\theta_{t+1}=\beta\left(C_{t}, H_{t}, H_{t-1}\right) \theta_{t}, \quad t \geq 0,
$$

where $\beta(\cdot)$ is the endogenous discount factor, $C_{t}$ and $H_{t}\left(H_{t-1}\right)$ denote the economy's average levels of consumption and contemporaneous (lagged) hours worked that are taken as given by the individual household. Moreover, $\beta\left(C_{t}, H_{t}, H_{t-1}\right)$ is postulated as

$$
\beta\left(C_{t}, H_{t}, H_{t-1}\right)=\left[1+C_{t}-\frac{A}{\omega}\left(H_{t}+\alpha H_{t-1}\right)^{\omega}\right]^{-\psi}, \psi>0 .
$$

\footnotetext{
${ }^{3}$ This modification introduces stationarity to the model's equilibrium dynamics in a computationally convenient manner. Schmitt-Grohé and Uribe (2003) show that other stationarity-inducing techniques lead to virtually identical quantitative results at business-cycle frequencies.

${ }^{4}$ Lettau and Uhlig (2000) examine the business-cycle effects of external habits in consumption (i.e., a consumption externality) and/or labor hours within closed-economy real business cycle models.
} 
Since $\psi>0$, the function $\beta(\cdot)$ is decreasing with consumption and increasing in the current labor supply. This feature in turn induces stationarity to the equilibrium dynamics such that the model's steady state is independent of its initial conditions.

The budget constraint faced by the representative agent is

$$
c_{t}+i_{t}+\left(1+r_{t-1}\right) d_{t-1}=y_{t}+d_{t}, \quad d_{-1} \text { is given, }
$$

where $i_{t}$ is gross investment, $r_{t-1}$ is the international real interest rate and $d_{t}$ is foreign debt. As in Letendre (2004), output $y_{t}$ is produced by the following Cobb-Douglas production function:

$$
y_{t}=z_{t}\left(u_{t} k_{t}\right)^{\mu} h_{t}^{1-\mu}, \quad 0<\mu<1,
$$

where $u_{t}$ denotes the rate of capital utilization that is endogenously determined by the representative household, and $k_{t}$ is physical capital. In addition, $z_{t}$ represents the technology shock that is assumed to evolve according to

$$
z_{t+1}=z_{t}^{\rho} \varepsilon_{t+1}, \quad 0<\rho<1 \text { and } z_{0}>0 \text { given, }
$$

where $\varepsilon_{t}$ is an i.i.d. random variable with unit mean and standard deviation $\sigma_{\varepsilon}$.

The law of motion for the capital stock is given by

$$
k_{t+1}=\left(1-\delta_{t}\right) k_{t}+i_{t}-\frac{\eta}{2}\left(k_{t+1}-k_{t}\right)^{2}, \eta>0 \text { and } k_{0}>0 \text { given, }
$$

where $\frac{\eta}{2}\left(k_{t+1}-k_{t}\right)^{2}$ represents the adjustment costs of net investment that are equal to zero at the non-stochastic steady state. We also postulate that the time-varying capital depreciation rate $\delta_{t} \in(0,1)$ takes the form

$$
\delta_{t}=\tau u_{t}^{\phi}, \quad \tau>0 \text { and } \phi>1,
$$

which indicates that more intensive capital utilization accelerates its rate of depreciation. When $\phi \rightarrow \infty$, our model collapses to one with constant depreciation and utilization rates, as in Mendoza (1991) and Schmitt-Grohé and Uribe (2003), among many others.

The first-order conditions for the representative household with respect to the indicated variables and the associated transversality conditions (TVC) are 


$$
\begin{aligned}
& c_{t}: \quad \lambda_{t}=\left[c_{t}-\frac{A}{\omega}\left(h_{t}+\alpha h_{t-1}\right)^{\omega}\right]^{-\gamma} \\
& h_{t}: A \lambda_{t}\left(h_{t}+\alpha h_{t-1}\right)^{\omega-1}+\alpha A \beta(\cdot) E_{t}\left[\lambda_{t+1}\left(h_{t+1}+\alpha h_{t}\right)^{\omega-1}\right]=(1-\mu) \lambda_{t} \frac{y_{t}}{h_{t}}, \\
& u_{t}: \frac{\mu}{\phi} \frac{y_{t}}{k_{t}}=\delta_{t} \\
& d_{t}: \lambda_{t}=\beta(\cdot)\left(1+r_{t}\right) E_{t} \lambda_{t+1}, \\
& k_{t+1}: \quad \lambda_{t}\left[1+\eta\left(k_{t+1}-k_{t}\right)\right]=\beta(\cdot) E_{t}\left\{\lambda_{t+1}\left[\mu \frac{y_{t+1}}{k_{t+1}}+1-\delta_{t+1}+\eta\left(k_{t+2}-k_{t+1}\right)\right]\right\} \\
& \mathrm{TVC}_{1}: \lim _{j \rightarrow \infty} E_{t}\left[\frac{d_{t+j}}{\prod_{s=0}^{j-1}\left(1+r_{t+s}\right)}\right] \leq 0, \\
& \mathrm{TVC}_{2}: \lim _{j \rightarrow \infty} E_{t}\left[\theta_{t+j} \lambda_{t+j} k_{t+1+j}\right]=0
\end{aligned}
$$

where $\lambda_{t}$ denotes the Lagrange multiplier on the budget constraint (5), which is equal to the marginal utility of consumption. Equation (11) governs the household's labor supply decision. Due to the presence of labor persistence, $h_{t-1}$ and $h_{t+1}$ both affect the household's period$t$ marginal utility cost of working for an additional unit of time, which in turn equals its marginal utility benefit. Equation (12) equates the marginal gain (more output) and marginal loss (higher capital depreciation) of a change in $u_{t}$. Combining (9) and (12) shows that the equilibrium rate of capital utilization is an increasing function of the marginal product of capital $\mu \frac{y_{t}}{k_{t}}$ and hours worked $h_{t}$. In addition, the household's intertemporal choices of foreign bonds are governed by (13), and condition (14) illustrates that the standard consumption Euler equation is modified to reflect the capital adjustment costs.

A competitive equilibrium is a set of processes $\left\{c_{t}, h_{t}, y_{t}, i_{t}, d_{t}, k_{t+1}, u_{t}, \delta_{t}, \lambda_{t}\right\}_{t=0}^{\infty}$ that satisfies equations (5)-(6) and (8)-(14), together with the productivity disturbances (7), the given initial conditions $z_{0}, h_{-1}, d_{-1}$ and $k_{0}$, and the transversality conditions (15)-(16). Moreover, 
the aggregate consistency condition requires that individual and per capita variables coincide, hence $c_{t}=C_{t}$ and $h_{t}=H_{t}$, for all $t$. Finally, the world's real interest rate is assumed to be a constant and given by $r_{t}=r$.

\section{Quantitative Results}

The preceding section presents the most "generalized" version of our model economy, which will be used to analyze six alternative specifications under different assumptions regarding capital utilization and labor persistence. Specifically, the first three configurations (Model 1, Model $1 a$ and Model $1 b$ ) postulate that capital utilization and depreciation rates are time-invariant. In addition, there is no labor persistence in Model $1(\alpha=0)$, whereas contemporaneous and lagged levels of hours worked are intertemporal substitutes and complements in Model $1 a$ $(\alpha>0)$ and Model $1 b(\alpha<0)$, respectively. The remaining three formulations (Model 2, Model $2 a$ and Model 2b) maintain the same qualitative feature of labor persistence (or the sign of $\alpha$ ) as their Model 1's counterparts, but exhibit endogenous capital utilization and depreciation rates.

To examine the quantitative business cycle properties of alternative models, we first derive the unique interior steady state in each specification, and then take log-linear approximations to the equilibrium conditions in its neighborhood. It is straightforward to show that each steady state is a saddle point, hence all versions of our model possess a unique rational expectations equilibrium. Next, we derive the economy's recursive equilibrium laws of motion as follows:

$$
\begin{aligned}
\hat{X}_{t+1} & =A \hat{X}_{t}+B \hat{z}_{t} \\
\hat{Y}_{t} & =C \hat{X}_{t}+D \hat{z}_{t}
\end{aligned}
$$

where hat variables denote logarithmic deviations from their steady-state values, $\hat{X}_{t}$ is the

state vector $\left\{\hat{k}_{t}, \hat{d}_{t-1}, \hat{h}_{t-1}\right\}, \hat{z}_{t}$ is the technology shock in deviation form and $\hat{Y}_{t}$ is a vector of (log-deviated) endogenous variables listed above. Moreover, we solve the conformable matrices $A, B, C$ and $D$ with the method of undetermined coefficients (see, for example, Campbell, 1994; Uhlig, 1999). 


\subsection{Model Calibration}

The model's structural parameters are calibrated to match the resulting steady-state values of key variables with the long-run features of the Canadian economy, reported in Letendre (2004), over the period 1981:1-2001:4. Each period in the model is taken to be one quarter. As in the previous studies, the capital share of national income, $\mu$, is chosen to be 0.32 ; the coefficient of risk aversion, $\gamma$, is set equal to 2 ; the parameter that governs the intertemporal elasticity of substitution in labor supply, $\omega$, is fixed at 1.7; and the international real interest rate is given by $r=0.007$, which in turn implies that the household's discount factor $\beta=0.993$ at the steady state.

We also follow Letendre (2004) and set the persistence parameter for the technology shock $\rho$ to be 0.94436 , and the standard deviation of its innovations $\sigma_{\varepsilon}$ to be 0.00599 when capital utilization and depreciation rates are constants $\left(u_{t}=u>0\right.$ and $\left.\delta=0.02\right)$ within Models 1 , $1 a$ and $1 b .{ }^{5}$ On the other hand, in the specifications with variable capital utilization (Models 2, $2 a$ and 2b), $\rho=0.93012$ and $\sigma_{\varepsilon}=0.00509$; moreover, given the above-mentioned value of $r$, we calibrate $\tau$ and $\phi$ in (9) such that the steady-state rates of capital depreciation and utilization respectively equal 0.02 and 0.816 , where the latter figure is identical to the average level observed in the Canadian economy. Next, in all six variants of our model economy, the preference parameter, $A$, is selected to ensure that the steady-state hours worked is 0.2 ; the elasticity parameter $\psi$ in (3) is calibrated to match the average ratio of trade balance to GDP in Canada $(=0.02)$ during the sample period; and the adjustment-cost parameter, $\eta$, is set to mimic the observed relative standard deviation of investment to output $(=2.97)$.

Finally, while there is no direct evidence on the labor-habit parameter $\alpha$ in Canada, there are several empirical studies that examine the degree of substitutability/complementarity in labor hours supplied (or leisure) over different periods for the U.S. economy, and the existing evidence is mixed. For example, Hotz, Kydland and Sedlacek (1988) provide empirical support for the presence of intertemporal substitutability (or the fatigue effects) of work effort from a PSID longitudinal data set on males. The estimated weight of past leisure on the "representative" individual's current utility, under a set of strictly exogenous instrumental variables, is 0.543 for the young and 0.754 for the old sample, respectively. Drawing on this result, we

\footnotetext{
${ }^{5}$ As mentioned in footnote 1, Mendoza (1991) and Schmitt-Grohé and Uribe (2003) calibrate $\rho(=0.42)$ and $\sigma_{\varepsilon}(=0.0129)$ in their fixed-utilization economy so that the model-generated time series of output exhibits the same variability and persistence as those observed in the Canadian data, $1946-1985$. We find that our simulation results, reported below, are qualitatively robust to this calibration strategy.
} 
choose the middle figure $\alpha=0.65$ in Models $1 a$ and $2 a$. By contrast, Eichenbaum, Hansen and Singleton (1988) and Wen (1998) find that the U.S. aggregate time series data favors the specification of intertemporal complementarity, and that the utility effect of lagged hours worked ranges from -0.832 to -0.625 . Therefore, $\alpha$ is set to take the midpoint value of -0.73 in Models $1 b$ and $2 b$.

Table 1 presents a set of simulated second moments from alternative versions of our model economy, each driven by an identical sequence of innovations to the technology shock, and compares them with the H-P filtered, post-1981 Canadian quarterly data documented by Letendre (2004). ${ }^{6}$ The statistics reported in columns 3-8 are sample means from 1,000 simulations of length 100 periods. We also employ Gregory and Smith's (1991) method to construct 95\% and $99 \%$ confidence intervals for each simulated statistical moment to evaluate its goodness of fit with the actual data. ${ }^{7}$

\subsection{Fixed Capital Utilization}

The first half of Table 1 presents our simulation results under fixed capital utilization. Model 1 is a canonical one-sector small open real business cycle economy driven solely by disturbances to the production technology. As the previous studies have shown, this benchmark specification is able to match the variability of the current-account-to-output ratio, the autocorrelations for the ratios of trade balance and current account to GDP, as well as the ranking of volatilities in consumption, output and investment with the Canadian quarterly detrended data. The model also does a reasonably good job in qualitatively mimicking the contemporaneous correlations with domestic output. However, Model 1 exhibits the following shortcomings: due to a weak internal propagation mechanism, the model-generated time series of GDP is not as volatile as that observed in the actual economy (although they are not statistically different at the $5 \%$ level of significance) $;^{8}$ more importantly, the coefficients of serial correlation in output, investment and work effort are all statistically lower than their empirical counterparts. In

\footnotetext{
${ }^{6}$ The savings-investment correlation $(0.77)$ is based on our own calculation from the same data set as in Letendre (2004).

${ }^{7}$ Specifically, under the null hypothesis that our theoretical model is true, we examine whether the historical sample statistics obtained from the data lie within the $95 \%$ or $99 \%$ confidence interval based on the distribution of 1,000 realizations of simulated moments. As in Letendre (2004), we use the superscripts ${ }^{* *}$ and ${ }^{*}$ to illustrate that an observed moment is not statistically different from its simulated counterpart at the $5 \%$ and $1 \%$ levels of significance, respectively. Moreover, the subscripts $\dagger \dagger$ and $\dagger$ respectively denote the $5 \%$ and $1 \%$ levels of statistical significance regarding the relative standard deviation of a variable to output.

${ }^{8}$ It is necessary to raise $\sigma_{\varepsilon}$ by 24 percent (from 0.00509 to 0.00630 ) to match the output varabilities in the model economy with that in the actual data.
} 
addition, the model predicts a counterfactual perfectly positive correlation between GDP and labor hours, a feature that is strongly rejected by the data at the $5 \%$ and $1 \%$ levels of statistical significance. ${ }^{9}$ This finding can be understood by substituting $\alpha=0$ (no labor persistence) into (11) to obtain

$$
A h_{t}^{\omega}=(1-\mu) y_{t}
$$

which shows that the household's labor supply decision is independent of the dynamics of consumption (there is no income effect), and that the elasticity of intertemporal substitution associated with work effort is zero. This property, together with the Cobb-Douglas production formulation, implies that the log-deviated output and employment are proportional to each other $\hat{y}_{t}=\omega \hat{h}_{t}$, for all $t$. The top panel of Figure 1 illustrates that a temporary one-percent rise in the technology shock leads to increases in $\hat{h}_{t}$ and $\hat{y}_{t}$ on impact, and then both variables return monotonically towards the steady state while maintaining their (linearly) deterministic relationship. This means that labor hours are perfectly correlated with GDP over the business cycle, i.e., $\operatorname{corr}\left(\hat{h}_{t}, \hat{y}_{t}\right)=1$.

On the other hand, although Model 1 correctly predicts that the ratios of trade balance and current account to output are countercyclical variables, it overstates the magnitude of their negative comovements. This result is caused by the high degree of serial correlation in the process that drives the productivity disturbance $(\rho=0.94436) .{ }^{10}$ If a less persistent technology shock is adopted, as in Mendoza (1991) and Schmitt-Grohé and Uribe (2003), then Model 1's predictions of these international correlation coefficients will be more quantitatively in line with the Canadian data.

In Models $1 a$ and $1 b$, the household's preferences (2) include current and previous quantities of labor supply that are postulated to be substitutes $(\alpha=0.65)$ and complements $(\alpha=-0.73)$, respectively. It turns out that both models perform no worse than the above baseline configuration at matching the observed contemporaneous correlations with GDP, whereas incorporating labor persistence into the analysis significantly improves these models' predictions of the serial correlations in key macroeconomic aggregates. In particular, as opposed to Model 1, the autocorrelations in output, investment and hours worked are not statistically different from the observed moments at the $5 \%$ level of significance.

\footnotetext{
${ }^{9}$ It follows that the correlation between output and average labor productivity (or the real wage rate in a decentralized equilibrium) is also equal to 1 .

${ }^{10}$ See Mendoza (1991, p. 807) for this point.
} 
Moreover, under the same driving process for generating aggregate fluctuations, allowing for intertemporal substitution (or the fatigue effects) raises the elasticity of labor supply with respect to changes in its marginal productivity. As a result, in contrast to Model 1, the standard deviation of hours worked is not statistically different from its empirical counterpart at the $5 \%$ level. However, output volatility in Model $1 a$, while higher than that in Model 1 , remains slightly lower than what the Canadian economy displays. On the contrary, intertemporal complementarity (or internal habit formation) in labor inputs within Model $1 b$ dampens the cyclical effects of technology shocks because agents are now reluctant to adjust their work effort. This feature thus leads to less variable hours worked and GDP in comparison with the benchmark Model 1.

Next, since the household's period- $t$ labor supply decision takes into account its expected influence on future utilities, output and employment are no longer perfectly correlated in Models $1 a$ and $1 b$. When either model is subject to a one-time positive innovation to the production technology, the contemporaneous level of work effort rises because of an outward shift of the labor demand curve, which in turn raises the current output as well. However, the dynamic responses after the impact period are quite different. In particular, the middle panel of Figure 1 shows that compared to Model 1, intertemporal substitutability in Model $1 a$ generates higher increases in hours worked and output at the initial period. Furthermore, the household's substituting work effort across periods leads to very similar oscillatory dynamics of $\hat{h}_{t}$ and $\hat{y}_{t}$ between $t=0$ and $t=3$ before they fall back gradually to the steady state. As a result, labor hours are strongly procyclical with $\operatorname{corr}\left(\hat{h}_{t}, \hat{y}_{t}\right)=0.99$, which is still statistically too high vis-á-vis the Canadian data.

By contrast, due to the presence of habit persistence, the bottom panel of Figure 1 shows that the initial responses of hours worked and output to a transient technology shock are smaller in Model $1 b$ than those in Model 1. Intertemporal complementarity also leads to a sluggish movement in the household's labor supply decision over different periods. It follows that $\hat{h}_{t}$ and $\hat{y}_{t}$ continue to rise after the impact period in spite of a decreasing marginal productivity of labor, thereby generating hump-shaped impulse response functions. Moreover, the subsequent adjustment paths of employment and output are not closely synchronized in that $\hat{y}_{t}$ peaks at $t=4$ whereas $\hat{h}_{t}$ reaches its maximum two periods later, indicating that labor hours now become a lagging variable of the business cycle. This results in a lower correlation coefficient between GDP and hours worked within Model $1 b(=0.92)$ that is remarkably 
close to the Canadian economy in which $\operatorname{corr}\left(\hat{h}_{t}, \hat{y}_{t}\right)=0.91$. Notice that this particular simulated moment is not statistically different from its empirical counterpart at the $5 \%$ level of significance.

\subsection{Variable Capital Utilization}

The second half of Table 1 presents our simulation results under variable capital utilization. To understand the macroeconomic effects of changing capital utilization, substituting (9) and (12) into (6) yields the following reduced-form social technology as a function of capital and labor inputs:

$$
y_{t}=\left(\frac{\mu}{\tau \phi}\right)^{\frac{\mu}{\phi-\mu}} z_{t}^{\frac{\phi}{\phi-\mu}} k_{t}^{\frac{\mu(\phi-1)}{\phi-\mu}} h_{t}^{\frac{\phi(1-\mu)}{\phi-\mu}},
$$

where $\frac{\mu(\phi-1)}{\phi-\mu}<1$ to rule out the possibility of sustained endogenous growth. Compared to the production function (6) with fixed capital utilization, (20) exhibits a larger equilibrium elasticity of output with respect to both the technology shock $z_{t}$ and labor hours $h_{t}$. This implies that varying capital utilization will amplify the quantitative effects of productivity disturbances because it enriches the model's endogenous propagation mechanism by providing an additional margin to change output. As a result, even with a smoother driving process $\left(\sigma_{\varepsilon}\right.$ is $13.36 \%$ smaller), all variables in Models 2, $2 a$ and $2 b$ display substantially higher standard deviations than their Model 1's counterparts. In addition, since the persistence parameter of productivity disturbances $\rho$ remains virtually unchanged, incorporating variable capital utilization does not significantly influence the model's predictions of autocorrelations, contemporaneous correlations with output and the savings-investment comovement.

As in Model 1, the no-labor-persistence Models 2 continues to show a counterfactual perfectly positive correlation between $\hat{h}_{t}$ and $\hat{y}_{t}$, and statistically lower serial correlations in GDP and hours worked than those observed in the data. On the other hand, Model $2 a$ (with intertemporal substitutability) "overshoots" the variabilities of output, consumption and investment, and underpredicts the autocorrelations in GDP and labor hours. By contrast, Model $2 b$ with habit formation in labor exhibits a statistically close match with the observed volatilities of output, investment and the trade-balance-to-output ratio (at the $5 \%$ level of significance) and consumption (at the $1 \%$ level of significance). However, the standard deviation of hours worked is statistically lower than the actual data because of the sluggish movements in employment caused by the intertemporal complementarity in work effort. In 
terms of serial correlations, Model $2 b$ successfully matches the persistence of GDP, investment, labor hours, and the ratios of trade balance and current account to output at the $5 \%$ level, and of consumption at the $1 \%$ level.

Figure 2 plots the impulse response functions for the three specifications with endogenous capital utilization. In comparison with Figure 1, the initial responses of hours worked and GDP to a transitory positive technology shock are stronger because of a larger equilibrium output elasticity. Moreover, higher work effort leads to more intensive utilization of capital, which in turn contributes to a further immediate rise in output. In sum, varying capital utilization strengthens the expansionary effects of a temporary productivity disturbance at the impact period. However, the ensuing dynamic responses of $\hat{h}_{t}$ and $\hat{y}_{t}$ in Models $2,2 a$, and $2 b$ are qualitatively identical to those in their fixed-utilization counterparts. If follows that the correlation coefficient between detrended output and labor hours is not affected by the addition of variable capital utilization alone. In particular, as in Model $1 b$, this correlation in Model $2 b$ continues to be statistically not different from its empirical counterpart at the $5 \%$ level of significance. Moreover, Model $2 b$ moves the contemporaneous correlations between output and the ratios of trade balance and current account to GDP in the right direction.

\subsection{Sensitivity Analysis}

So far, our analysis has shown that Model $2 b$, which is a small open, technology-shock driven one-sector real business cycle model with variable capital utilization and internal habit formation in labor hours, is able to account for the main empirical regularities of Canada's aggregate fluctuations after 1981. Since the labor-persistence parameter $\alpha(=-0.73)$ is not calibrated from the Canadian data, Table 2 presents simulation results and the corresponding statistical significances under alternative degrees of intertemporal complementarity in work effort. It turns out that most of the autocorrelations, contemporaneous correlations with GDP and the savings-investment comovement are quantitatively and statistically robust to variations of $\alpha$. However, when the absolute value of $\alpha$ rises, agents are less willing to adjust their labor supplies across successive time periods. As a result, the volatilities of hours worked, output, consumption and investment are all negatively related to the strength of intertemporal complementarity in labor. In addition, slower changes in work effort lead to a weaker comovement

between GDP and employment over the business cycle, i.e., $\frac{\partial \operatorname{corr}\left(\hat{h}_{t}, \hat{y}_{t}\right)}{\partial|\alpha|}<0$. 


\section{Conclusion}

Previous studies have found that it is difficult to account for some of Canada's real businesscycle characteristics in a canonical dynamic small open economy model driven by technology shocks. Specifically, in Mendoza's (1991) formulation with a time separable utility function, zero elasticity of intertemporal substitution in work effort leads to a counterfactual perfectly positive correlation between GDP and hours worked. Moreover, due to a weak internal propagation mechanism, the volatilities and persistence of several model-generated time series are statistically lower than those observed in the Canadian data. In this paper, we show that adding intertemporally nonseparable labor supply and variable capital utilization to the Mendoza economy can overcome these shortcomings. Under a time nonseparable preference formulation, the household's period-t labor supply decision also depends on previous and future quantities of hours worked, hence GDP and employment are no longer perfectly correlated over the business cycle. On the other hand, varying capital utilization enhances the cyclical effects of productivity disturbances because it provides an additional channel to change output. Overall, our analysis shows that incorporating intertemporal complementarity in labor hours and endogenous capital utilization into Mendoza's dynamic, small open economy model can better explain the quantitative business cycle properties of real macroeconomic variables in the post-1981 Canadian economy.

Although our model provides an improved fit with the Canadian business cycle along several important dimensions, it nevertheless exaggerates the procyclical nature of consumption and investment. To address this inconsistency, it would be worthwhile to incorporate other sources of driving uncertainties, such as preference shocks (Baxter and King, 1991) or termsof-trade shocks (Bergin and Sheffrin, 2000), into the analysis. ${ }^{11}$ Moreover, Laxton and Pesenti (2003) and Letendre (2004), among others, have made a case for the introduction of habit formation in consumption with reasonable success for small open economies. Hence, it would be interesting to study the cyclical effects of habit formation in consumption as well as in labor hours within a dynamic, small open real business cycle model. Finally, it would be valuable to examine alternative preference specifications, e.g. the recursive utility framework as in Lettau and Uhlig (2000) and Tallarini (2000). This will allow us to investigate the robustness

\footnotetext{
${ }^{11}$ Mendoza (1991), Correia, Neves and Rebelo (1995), and Letendre (2004), among others, have shown that adding shocks to government spending and/or the world interest rate does not improve the overall fit of the class of models that we have examined in this paper.
} 
of our results, and further identify model features and parameters that affect the aggregate fluctuations in a small open economy like Canada. We plan to pursue these research projects in the future. 


\section{References}

[1] Baxter, Marianne and Robert G. King, "Productive Externalities and Business Cycles," Institute for Empirical Macroeconomics at Federal Reserve Bank of Minneapolis, Discussion Paper 53, November 1991.

[2] Bergin, Paul R. and Steven M. Sheffrin, "Interest Rates, Exchange Rates and the Present Value Models of the Current Account," Economic Journal 110(2000), 535-558.

[3] Burnside, C.A., M.S. Eichenbaum and S. Rebelo, "Labor Hoarding and the Business Cycle," Journal of Political Economy 101(1993), 245-273.

[4] Burnside, C.A. and M.S. Eichenbaum, "Factor-Hoarding and the Propagation of BusinessCycle Shocks," American Economic Review 86(1996), 1154-1174.

[5] Campbell, J.Y., "Inspecting the Mechanism: An Analytical Approach to the Stochastic Growth Model," Journal of Monetary Economics 33(1994), 463-504.

[6] Correia, I., J.C. Neves and S.T. Rebelo, "Business Cycles in a Small Open Economy," European Economic Review 39(1995), 1089-1113.

[7] Eichenbaum, M.S., L.P. Hansen and K.J. Singleton, "A Time Series Analysis of Representative Agent Models of Consumption and Leisure Choice Under Uncertainty," Quarterly Journal of Economics 103(1988), 51-78.

[8] Greenwood, J., Z. Hercowitz, and G.W. Huffman, "Investment, Capacity Utilization, and the Real Business Cycle, American Economic Review 78(1988), 402-417.

[9] Gregory, A.W. and G.W. Smith, "Calibration as Testing: Inference in Simulated Macroeconomic Models," Journal of Business 83 Economic Statistics 9(1991), 297-303.

[10] Hotz, V.J., F.E. Kydland and G.L. Sedlacek, "Intertemporal Preferences and Labor Supply," Econometrica 56(1988), 335-360.

[11] Kydland, F.E. and E. Prescott, "Time to Build and Aggregate Fluctuations", Econometrica, 50(1982), 1345-1370.

[12] Laxton, Douglas and Paolo Pesenti, "Monetary Rules for Small, Open, Emerging Economies," Journal of Monetary Economics 50(2003), 1109-1146.

[13] Letendre, M.-A., "Capital Utilization and Habit Formation in a Small Open Economy," Canadian Journal of Economics 37(2004), 721-741.

[14] Lettau, M. and H. Uhlig, "Can Habit Formation be Reconciled with Business Cycle Facts?" Review of Economic Dynamics, 3(2000), 79-99.

[15] Mendoza, E.G., "Real Business Cycles in a Small Open Economy," American Economic Review 81(1991), 797-818.

[16] Schmitt-Grohé, S. and M. Uribe, "Closing Small Open Economy Models," Journal of International Economics 61(2003), 163-185.

[17] Tallarini, Thomas D. Jr., "Risk-Sensitive Real Business Cycles," Journal of Monetary Economics 45(2000), 507-532.

[18] Uhlig, H., "A Toolkit for Analyzing Nonlinear Dynamic Stochastic Models," in Computational Methods for the Study of Dynamic Economies, edited by R. Maromon and A. Scott, Oxford: Oxford University Press, 1999, 30-61. 
[19] Uzawa, H., "Time Preference, the Consumption Function, and Optimum Asset Holdings," in Value, Capital, and Growth: Papers in Honour of Sir John Hicks, edited by J.N. Wolfe, Edinburgh: Edinburgh University Press, 1968, 485-504.

[20] Wen, Y., "Can A Real Business Cycle Model Pass the Watson Test?" Journal of Monetary Economics 42(1998), 185-203. 
Table 1: Observed and Simulated Second Moments

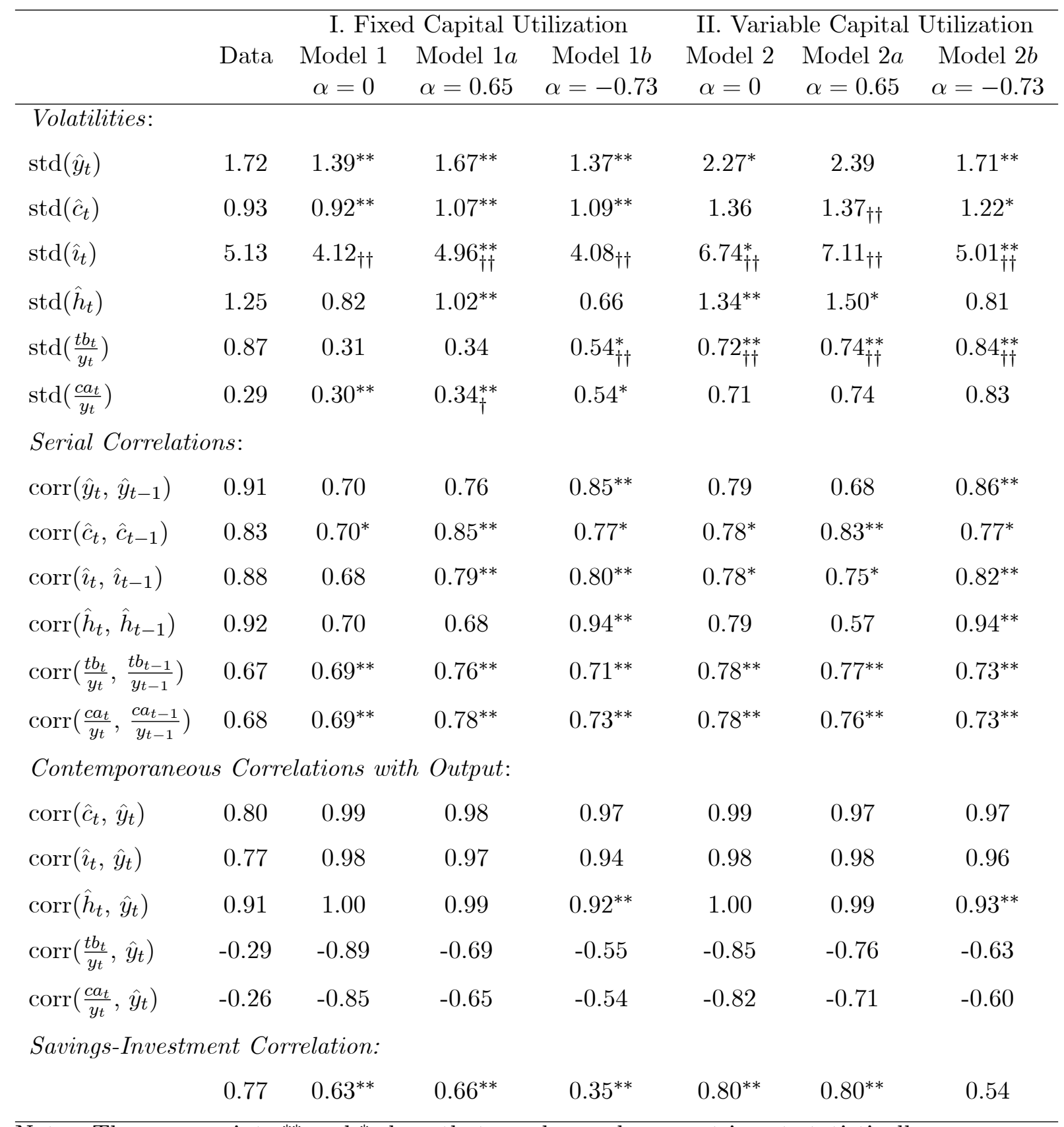

Notes: The superscripts ${ }^{* *}$ and ${ }^{*}$ show that an observed moment is not statistically different from its simulated counterpart at the $5 \%$ and $1 \%$ levels of significance, respectively. The subscripts $+t$ and + show that the observed relative standard deviation of a variable to that of output is not statistically different from its simulated counterpart at the $5 \%$ and $1 \%$ levels of significance, respectively. 
Table 2: Variable Capital Utilization and Internal Habits in Labor Supply

\begin{tabular}{|c|c|c|c|c|c|c|}
\hline & Data & $\alpha=-0.1$ & $\alpha=-0.3$ & $\alpha=-0.5$ & $\alpha=-0.7$ & $\alpha=-0.9$ \\
\hline \multicolumn{7}{|l|}{ Volatilities: } \\
\hline $\operatorname{std}\left(\hat{y}_{t}\right)$ & 1.72 & $2.37^{*}$ & $2.16^{* *}$ & $2.03^{* *}$ & $1.77^{* *}$ & 1.24 \\
\hline $\operatorname{std}\left(\hat{c}_{t}\right)$ & 0.93 & 1.36 & 1.34 & 1.31 & 1.24 & $0.96^{* *}$ \\
\hline $\operatorname{std}\left(\hat{\imath}_{t}\right)$ & 5.13 & $6.65_{\dagger \dagger}^{* *}$ & $6.41_{\dagger \dagger}^{* *}$ & $6.02_{\dagger \dagger}^{* *}$ & $5.27_{\dagger \dagger}^{* *}$ & $3.69_{\dagger \dagger}$ \\
\hline $\operatorname{std}\left(\hat{h}_{t}\right)$ & 1.25 & $1.30^{* *}$ & $1.22^{* *}$ & 1.10 & 0.87 & 0.33 \\
\hline $\operatorname{std}\left(\frac{t b_{t}}{y_{t}}\right)$ & 0.87 & $0.73_{\dagger \dagger}^{* *}$ & $0.77_{\dagger \dagger}^{* *}$ & $0.83_{\dagger \dagger}^{* *}$ & $0.85_{\dagger \dagger}^{* *}$ & $0.61_{\dagger \dagger}^{* *}$ \\
\hline $\operatorname{std}\left(\frac{c a_{t}}{y_{t}}\right)$ & 0.29 & 0.73 & 0.76 & 0.82 & 0.82 & $0.49^{*}$ \\
\hline \multicolumn{7}{|c|}{ Serial Correlations: } \\
\hline $\operatorname{corr}\left(\hat{y}_{t}, \hat{y}_{t-1}\right)$ & 0.91 & $0.80^{*}$ & $0.83^{*}$ & $0.85^{*}$ & $0.86^{*}$ & $0.82^{*}$ \\
\hline $\operatorname{corr}\left(\hat{c}_{t}, \hat{c}_{t-1}\right)$ & 0.83 & $0.78^{*}$ & $0.78^{*}$ & $0.77^{*}$ & $0.77^{*}$ & $0.78^{*}$ \\
\hline $\operatorname{corr}\left(\hat{\imath}_{t}, \hat{\imath}_{t-1}\right)$ & 0.88 & $0.79^{* *}$ & $0.80^{* *}$ & $0.81^{* *}$ & $0.82^{* *}$ & $0.80^{* *}$ \\
\hline $\operatorname{corr}\left(\hat{h}_{t}, \hat{h}_{t-1}\right)$ & 0.92 & 0.82 & 0.87 & $0.90^{* *}$ & $0.94^{* *}$ & $0.96^{* *}$ \\
\hline $\operatorname{corr}\left(\frac{t b_{t}}{y_{t}}, \frac{t b_{t-1}}{y_{t-1}}\right)$ & 0.67 & $0.74^{* *}$ & $0.69^{* *}$ & $0.67^{* *}$ & $0.72^{* *}$ & $0.78^{* *}$ \\
\hline $\operatorname{corr}\left(\frac{c a_{t}}{y_{t}}, \frac{c a_{t-1}}{y_{t-1}}\right)$ & 0.68 & $0.75^{* *}$ & $0.67^{* *}$ & $0.66^{* *}$ & $0.72^{* *}$ & $0.79^{* *}$ \\
\hline \multicolumn{7}{|c|}{ Contemporaneous Correlations with Output: } \\
\hline $\operatorname{corr}\left(\hat{c}_{t}, \hat{y}_{t}\right)$ & 0.80 & 0.99 & 0.99 & 0.99 & 0.97 & 0.98 \\
\hline $\operatorname{corr}\left(\hat{\imath}_{t}, \hat{y}_{t}\right)$ & 0.77 & 0.98 & 0.97 & 0.96 & 0.96 & 0.97 \\
\hline $\operatorname{corr}\left(\hat{h}_{t}, \hat{y}_{t}\right)$ & 0.91 & 0.99 & 0.99 & 0.98 & $0.94^{* *}$ & 0.66 \\
\hline $\operatorname{corr}\left(\frac{t b_{t}}{y_{t}}, \hat{y}_{t}\right)$ & -0.29 & -0.83 & -0.77 & -0.69 & -0.63 & -0.78 \\
\hline $\operatorname{corr}\left(\frac{c a_{t}}{y_{t}}, \hat{y}_{t}\right)$ & -0.26 & -0.80 & -0.74 & -0.66 & -0.62 & -0.78 \\
\hline \multicolumn{7}{|c|}{ Savings-Investment Correlation: } \\
\hline & 0.77 & $0.79^{* *}$ & $0.74^{* *}$ & $0.67^{* *}$ & $0.57^{*}$ & 0.48 \\
\hline
\end{tabular}


Figure 1: Fixed Capital Utilization
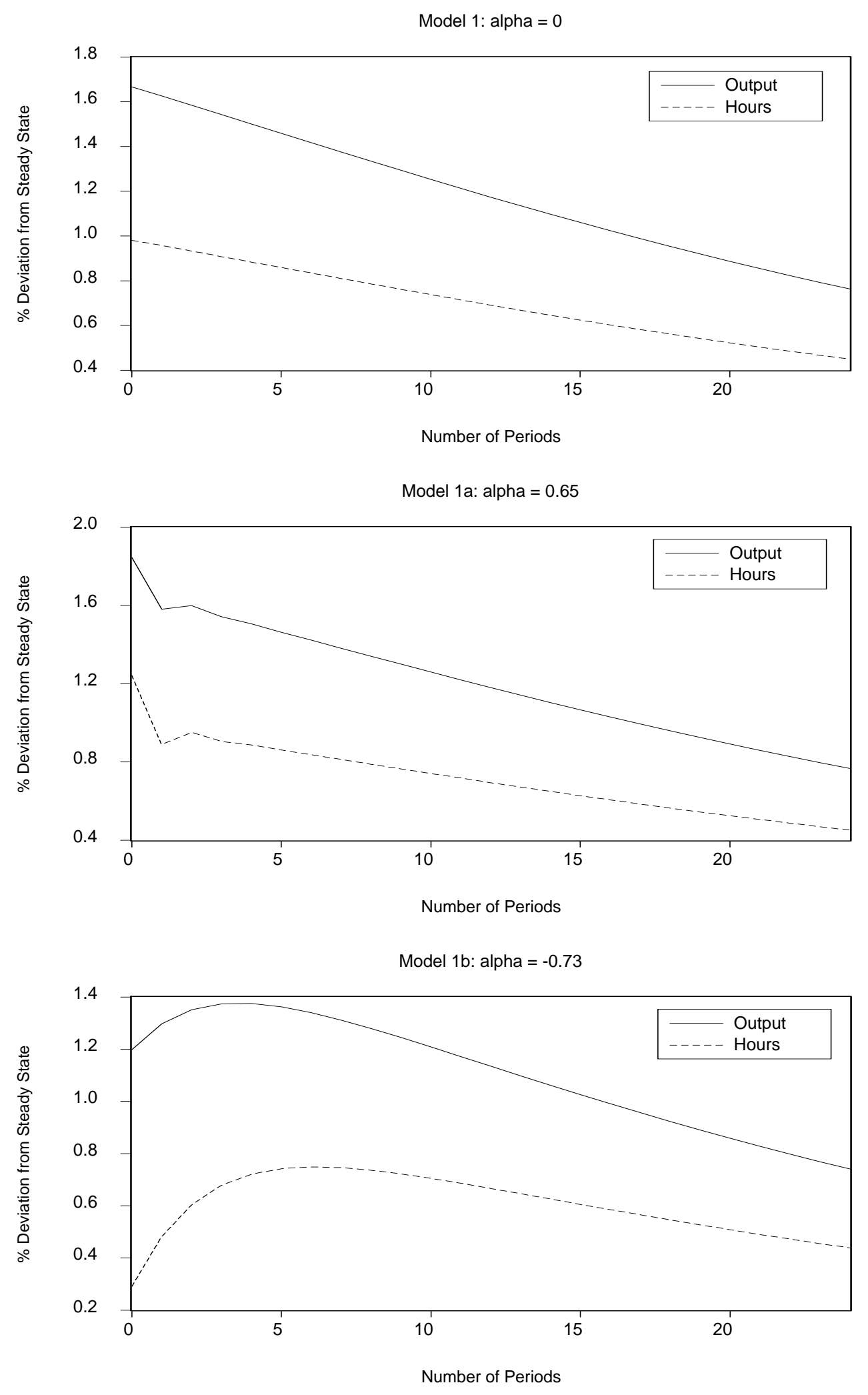
Figure 2: Variable Capital Utilization
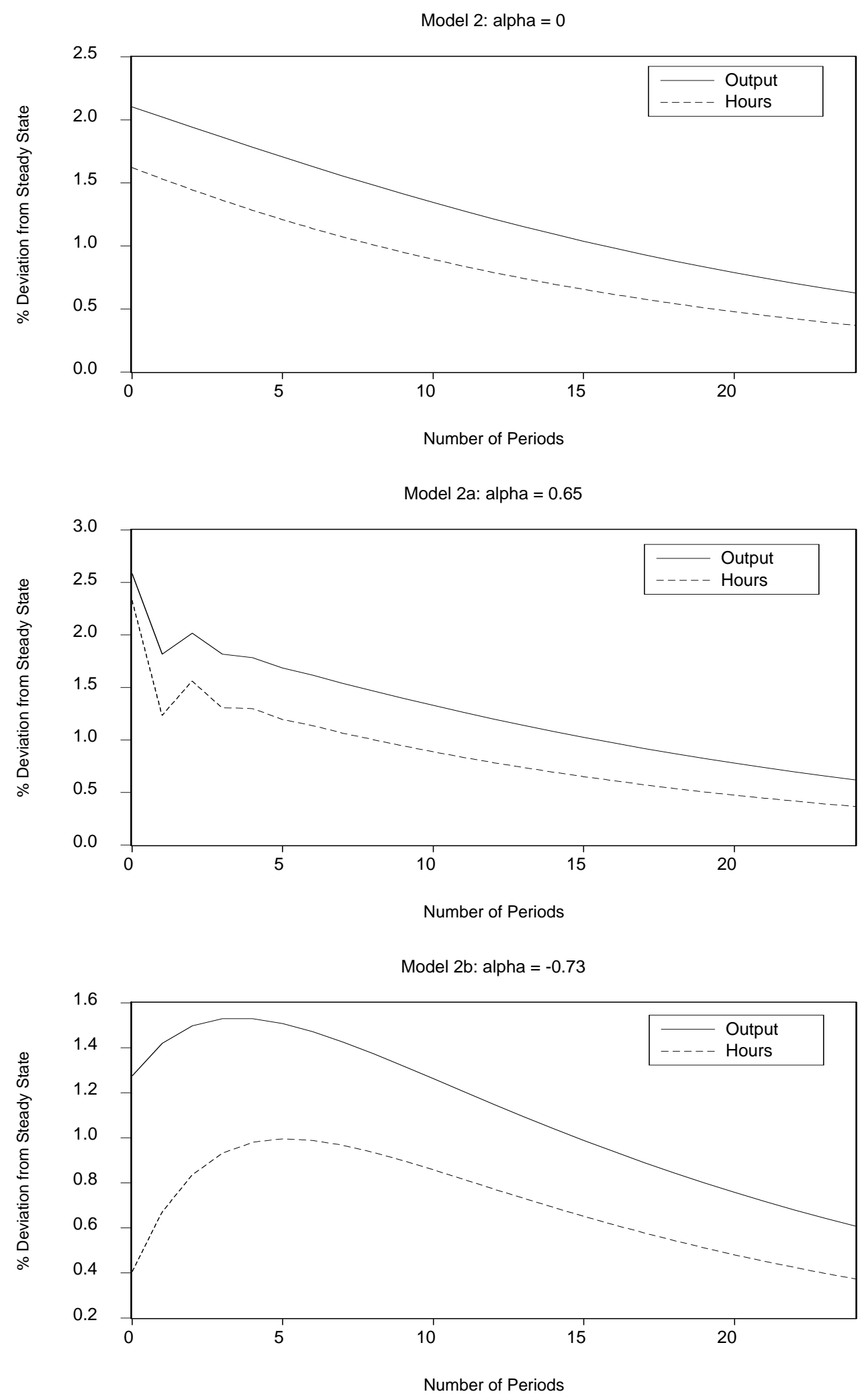